\title{
VARIACIÓN DIALECTAL NO PERÍODO DE EMERXENCIA
}

\author{
Rosario Álvarez \\ Instituto da Lingua Galega (USC)
}

As linguas non teñen data nin certificado de nacemento, nin sequera podemos dicir con propiedade que "nacen", por iso ninguén poderá precisar, cunha certa marxe de seguridade, en que intre unha modalidade lingüística dada deixou de ser latín para pasar a ser galego, nin que trazo ou trazos marcan tal acontecemento; engádase que nese tránsito entre dúas linguas é imposible cuantificar de forma obxectiva canto material lingüístico permanece da lingua de partida, canto é compartido por ambas e canto hai que atribuír en exclusiva á nova lingua, en todas as súas modalidades. Nin sequera é tarefa doada establecer en que momento emerxeu realmente como lingua escrita, pois descoñecemos ata que punto o modelo gráfico dalgúns textos é unha versión escrita non fonémica e por iso distanciada da realidade oral coetánea.

Encargóusenos esculcar en textos galegos anteriores a 1260 e desvelar os indicios de variación dialectal, entendendo que esa é unha data convencional que pon termo ao período de emerxencia do galego como lingua escrita. Por fortuna, os avances sobre o coñecemento da nosa historia lingüística producidos nas últimas décadas van acompañados da localización e lectura dun número cada vez maior de textos desta época auroral, de xeito que puidemos reunir un monllo de 38 textos seleccionados sobre o que nos apoiar. Figuran todos nunha táboa en apéndice, cos datos espaciais e temporais e mais coa forma de cita adoptada neste traballo; agradecemos aos seus colectores e editores que nos facilitasen a información e leccións de que dispuñan, anticipándonolos á súa edición definitiva. Facilitounos tamén a tarefa poder contar coa base de datos do Tesouro medieval informatizado da lingua galega (TMILG), ao que remitimos para os datos de textos que non pertencen ao corpus citado.

Distribuímos a nosa contribución en dúas partes. Na primeira presentamos con exemplos prácticos algunhas das grandes dificultades con que nos enfrontamos os investigadores da variación lingüística histórica, en particular 
no ámbito da filoloxía galega. Coidamos que este marco inicial é necesario, tanto por sentar unhas mínimas bases metodolóxicas coma por advertir da necesaria prudencia con que hai que tomar conclusións parciais que terán que ser revisadas no futuro, conforme se vaian achegando novos textos e novos datos. A segunda parte dedícase á análise diatópica destes textos, sen pretensións de exahustividade, comentando unha serie de trazos que presentamos organizados en tres grupos, que se corresponden coas tres liñas conclusivas sobre o valor destes textos iniciais desde o punto de vista da variación.

\section{Dificultades metodolóxicas e Viabilidade Dunha dialectoloxía MEDIEVAL}

1. En xeral sábese pouco dos autores medievais e da súa orixe xeográfica. Avances significativos na investigación producidos nas últimas décadas vannos permitindo saber cada vez máis da cronoloxía e dos lugares de procedencia dos poetas, xunto con outros datos biográficos que deixan enxergar a que outras influencias lingüísticas puideron estar sometidos. É un lugar común referirse á lingua dos cancioneiros como un rexistro case artificial de tan fosilizado, unha sorte de a priori que, en canto se fan pesquisas lingüísticas de certo pormenor, axiña se revela menos consistente do que se presumía inicialmente. En todo caso falta un estudo abranguente da variación interna deste corpus textual, posta en relación sexa coas coordenadas dos seus autores sexa coas dos seus compiladores.

Por poñermos un exemplo da importancia desta información para o labor dos lingüistas, baseado na experiencia propia, tomamos a licenza de remitir a un noso traballo recente a propósito da variación NOSCO : CONNOSCO : CON Nós, onde puidemos comprobar como as variantes con /u/ se limitan á lingua da poesía, ben a través de CSM ben da compilación recollida no Cancioneiro da Ajuda, nun e noutro caso en concorrencia co maioritario $<\mathrm{O}>$ (Álvarez 2004) ${ }^{1}$. Perante esta constatación caben varias hipóteses razoables: (a) que as formas en $<\mathrm{u}>$, características dos romances hispánicos centrais, sexan en todos estes casos interferencias lingüísticas explicables volta polas estadías dos poetas en territorios do leonés, castelán ou aragonés, volta pola lingua de instalación ou o bilingüismo dos seus compiladores; (b)

1. Os testemuños presentes en cantigas tamén transmitidas por B [Cancioneiro da Biblioteca Nacional] ou $V$ [Cancioneiro da Vaticana] mostran invariablemente $<\mathrm{O}>$, aga no refrán dunha cantiga de amigo onde ambos presentan tamén $<\mathrm{u}>$. 
que sexan formas de variedades lingüísticas antigas que non prosperaron nin a través das compilacións posteriores (os apógrafos italianos) nin da prosa, máis tardía, pois pódese comprobar que se ben as dúas opcións $<\mathrm{u}, \mathrm{o}>$ aparecen en todo o período, os poetas activos antes de mediados do século XIII presentan $<\mathrm{u}>$ (claro que, segundo o que hoxe sabemos da primeira xeración trobadoresca, a datación coincide cunha maior exposición aos romances centrais [Oliveira 1994 e 2001, Miranda 2004a]); (c) que se trate dunha característica diatópica, pois case todos os poetas que empregan $<\mathrm{u}>$ proceden dunha rexión occidental localizada entre o Douro e o Miño, onde, segundo Maia, hai que buscar a orixe da propagación de solucións do tipo isto (1986: 417, 689-690). Así pois, a pesar do presunto efecto homoxeneizador da compilación, a variación interna do corpus lírico é unha realidade; a súa descrición lingüística, coma a de toda a lingua medieval, precisa da localización de cada testemuño nas coordenadas espacial e temporal.

Coñécese moito menos dos promotores e dos autores das traducións e obras en prosa, e xa que logo de a onde referirmos as variantes. Grazas a unha anotación de Fernán Martís, sabemos que o texto galego da Crónica Troiana foi encargado por Fernán Pérez de Andrade, que foi rematado en 1373 e que se deben á súa man os 100 primeiros folios e mais un caderno cos folios 119v-128v; ora ben, de "escriuj este liuro" non se pode inferir sen marxe de dúbida que o capelán Fernán Martís é o verdadeiro tradutor e non un simple copista, e doutra parte nada se nos di da factura do resto da obra, nin sequera cantas outras mans participaron (Lorenzo 1985: 76-79). Cando nos falta un Fernán Martís cómpre acudir a técnicas de investigación paleográfica, codicolóxica e lingüística. Por este medio púidose chegar a establecer tres partes na tradución galega da Crónica Geral (fins do século xiII), pois na análise codicolóxica do ms. 8817 feita polo editor indícase que no folio $32 \mathrm{bV}$ hai un espazo de oito liñas en branco (ao final do cap. 73 e antes do 74) e que os folios 65abR e 65aV, con letra maior e máis espallada, van seguidos de 65bV, onde só hai unha receita, escrita catro veces con letra distinta (entre os cap. 138 e 139) (Lorenzo 1975: XXXVII); unha análise similar tamén puxo de relevo que Miragres de Santiago (c. 1400) é un volume facticio, integrado por cinco fragmentos de procedencia e datación descoñecidas (Gómez Clemente 2001).

Así pois, para traballarmos en perspectiva diacrónica e diatópica só os documentos notariais poden ofrecer datos con que configurar a rede básica sobre a que localizarmos logo as obras literarias, en función de que presenten uns ou outros trazos. Este foi o procedemento seguido por nós no estudo da variación lingüística da tradución da Crónica Geral, a través do ms. 8817 (Álvarez / Xove 1998). Por medio da cartografía dunha serie de trazos 
con variación diatópica ${ }^{2}$, mostramos que, con variantes entre os escribentes, o texto corresponde a unha variedade occidental con algúns trazos inequivocamente tudenses, sen que se observen outros que, no nivel de coñecemento actual, contradigan esta localización. Máis aínda, o estudo da variación interna levounos a concluír que houbo diferentes mans e que os trazos lingüísticos que as identifican concordan coas tres partes establecidas por medio da análise codicolóxica. Valla como mostra o emprego que fan das variantes dos demostrativos autónomos, con /i/ ou /e/ no galego tudense (cf. $\$ 2,1 \mathrm{~d}$ ): o tradutor da primeira parte (cap. 1-73, inclusives) prefire isto e ysto $(73,43 \%$ e $2,1 \%$, respectivamente) fronte a esto $(24,47 \%)$; o da segunda opta por esto $(96,04 \%)$, deixando ysto $(3,47 \%)$ e isto $(0,49 \%)$ en posición minoritaria; o da terceira corrixe un tanto esta tendencia, pero segue preferindo esto $(73,53 \%)$ fronte a ysto $(19,61 \%)$ e isto $(6,86 \%)$. Ademais, apreciamos diferenzas de grao entre os tres tamén noutros trazos; así, por exemplo, a primeira man mostra maior frecuencia de riscos máis caracteristicamente tudenses ao preferir tamén as variantes logar, - e final en ele e aquele, a raíz ou(u)en \{oír, ouvir...\} ou os dativos de 3P en -i (lli, llis).

2. Mais, para podermos tecer esa rede, cómpre establecer quen é o autor real do documento notarial para logo situalo nas coordenadas espaciais e temporais correctas. Non sempre consta o nome de quen redacta o documento ou garante a súa veracidade, pero mesmo a mención clara destas persoas non despexa todas as dúbidas nin achanza todas as dificultades. Así, cunha anotación do tipo "Pelagius Iohannjs notuijt" coñecemos o nome de quen toma nota rexistral do pactado o día 1 de marzo de 1256 entre a abadesa de Sobrado de Trives e dous veciños sobre unha herdade en Vilanova, en presenza dunha serie de participantes que serven de testemuñas, entre eles monxas e clérigos, cos seus nomes; por outros documentos coetáneos e coterráneos des que non sempre se dispón- chegamos a saber que se trata dun presbítero, por tanto dun home non de leis pero si letrado. Situamos o texto en Sobrado de Trives, aínda sen sabermos se o escribente é

2. Presentamos alí dez trazos, que non esgotan a relación dos posibles e significativos: as variantes de enpos, apos, depos, depoys... en contexto preposicional; a expresión do plural no pronome persoal dativo de terceira persoa, na forma pronominal simple (lli/lis, lle/lles, le/les) ou na amálgama llo/llelo; a vogal da forma do pronome persoal dativo de $3 \mathrm{P}$ (lli ou lle, coas respectivas variantes); as formas do pronome persoal P3 (el, ele, elle) e do demostrativo tipo III (aquel, aquele, aquelle); as formas dos demostrativos autónomos (isto, esto...); a existencia do pronome de alteridade autónomo outre : outri : outren 'outra persoa' e a variación outro : autro do pronome determinante; a variación na preposición ontre \{ontre, untre\} e entre \{entre, intre\}; a vogal pretónica en muller: moller e lugar : logar; as formas variantes do radical do verbo oír: ouir : ouuir; e a vogal tónica no contexto monge : munge e nome : nume. 
ou non da veciñanza, nin se reelabora o texto na súa variedade lingüística ou toma nota literal (e neste suposto, ignoramos a que variedade lingüística se adscribe quen dita, etc.). O mesmo ocorre con outras fórmulas máis precisas, do tipo "Eu Lourenco Eanes, notario del rey, a esto fuy presente $e$ escriuj $e$ poño y meu nome e synal" (documento dado c1253 en "Sancta Maria d'Ooure"), pois subsisten os problemas de non sabermos cal é a adscrición dialectal do notario, que se proclama de forma inequívoca autor do texto. E cando o desenvolvemento do notariado fai que se empreguen fórmulas do tipo «Et eu, Vaasco Lopes, de Chantada, notario publico ena dita vila ( . . et esta carta en mjna presença fis escripuyr" (1421 Monforte), a pesar da mención do notario, a construción factitiva déixanos sen saber quen escribiu realmente o texto ${ }^{3}$.

Ignoramos ata que punto os notarios e os escribáns que traballan na notaría son da contorna, pero non semella fóra de lugar que ou sexan da veciñanza ou teñan certo carácter de permanencia; cando o escribente é un frade hai menos garantías de que proceda da contorna inmediata. Cómprenos un mellor coñecemento sobre a figura do notario, as liñas de sucesión no exercicio do cargo nos mesmos lugares, a función da notaría como centro de aprendizaxe do oficio, a mobilidade dos que acadasen un dominio aceptable, a forma de selección e contratación, etc. Son moitas as preguntas que se agolpan, con repercusión para o estudo lingüístico: ¿o notario é veciño da xurisdición onde exerce o cargo ou había mobilidade de servidores públicos?, ¿ata que punto a lingua dos declarantes inflúe sobre a lingua do redactor?, ¿que axuda efectiva puido recibir o notario dos escribáns da súa oficina?, ¿O estilo dos documentos está próximo ou afastado doutros estilos coexistentes, moito máis do dominio común? ${ }^{4}$, etc. Entre elas salientan as que teñen que ver coa aprendizaxe, pois na medida en que nun centro dado se accede ás destrezas da escritura e a un código do oficio nen poderían faltar un aparato formulario e un certo estilo lingüístico dominante- cabe supoñer que iso implica, en maior ou menor medida, unha ampliación dos

3. Outras fórmulas usuais, como a frase "esta karta robor[o] et confirmo", non se refiren á autoría material do texto; non o fai, p. ex., no foro do burgo de Castro Caldelas, pois é evidente que non foi redactado polo mesmísimo rei don Afonso.

4. No marco do simposio Na nosa lyngoage galega, que se recolle neste volume, o profesor Fernández de Viana, preguntado sobre o particular, afirmou sen marxe de dúbida que en efecto os notarios eran veciños do lugar e confirmou que a aprendizaxe se producía no obradoiro notarial, onde o notario actuaba como mestre que ensina un oficio. Cadra isto coa recomendación de Afonso X de que o notario debe coñecer a sociedade e o medio en que exerce o oficio (cf. capítulo de Gutiérrez / Cabana), e mais coa detección de sagas familiares, a través de patronímicos que se suceden no mesmo lugar ou se espallan pola contorna, como sinalou H. Monteagudo na súa intervención. 
recursos lingüísticos propios e o punto de arrinque de procesos de abandono por substitución 5 .

Os criterios empregados para adscribir territorialmente a lingua dun documento son discutibles, e de seguro non se poderán establecer de forma apriorística nin xeral para todos os casos. Con todas as cautelas posibles, nós non procuramos tanto unha localización precisa coma unha área ou rexión, e para iso tomamos en consideración os datos seguintes, presentados en orde de importancia; por lle facilitar a localización ao lector moderno, nalgúns casos tomamos como referencia xeográfica o actual concello:

(a) O lugar que se consigna en relación co notario ou escribán: «Johan de Santiago, notario de Portomarĩ, notuit" (1255-Portomarín), "Johã Ffernandez, notario de Soueroso <lo $>$ scriuj" (1255-Sobroso).

(b) O lugar onde se outorga o documento: “Feyta en Sancta Maria d'Ooure", Pontedeume (c1253-Ombre), "dada ena Ramalosa", Baiona/Nigrán (1253-Ramallosa).

(c) O lugar ou lugares directamente vencellados á transación ou aos protagonistas principais. En 1233-Melón/Covelo, "Varzena de Mera" [Barcia de Mera-Covelo] únese ás mencións do convento de Melón e á presenza do abade e de varios monxes, polo que o documento é, para nós, de Covelo/Melón. Algo similar ocorre con 1231-Melón/Borbén, pois, ao non se mencionar onde se fai o documento nin a residencia ou xurisdición de quen o escribe, tanto podemos atribuílo a Pazos de Borbén, onde se atopan o vendedor e a súa herdade, ou a Melón, onde están os compradores. Todas as propiedades do testamento de Pedro Fernández corresponden ao actual concello do Corgo, por iso chamamos 1240-Corgo ao cuarto documento da nosa táboa; os topónimos vencellados a outros participantes confirman a rodeada de Lugo. Os fragmentos de proba dun preito atribuídos a Sobrado, por formar parte da súa colección documental, foron nomeados por nós c1242-Friol, porque todo o asunto se refire a herdades e persoas de Xiá (Friol), sen que conste nin de onde é o xuíz nin onde se redactan os documentos. Nomeamos 1247-Páramo o documento de 6-IV-1247 da colección de Ferreira de Pallares, porque se atopan na fregresía de Vilarmosteiro todas as propiedades que ceden a Mo-

5. Non estará de máis advertir que non é esperable que a lingua escrita sexa un puro traslado da lingua oral ao pergamiño ou papel, porque esa non é súa función e porque habitualmente non ocorre así, e iso mesmo aceptando que no acto rexistral sexa plausible unha estreita correspondencia oralidade-escrita. Aínda no caso de que se produza certa identidade, non é desbotable que se trasladen á escrita formas variantes ás que se concede, por razóns sociolingüísticas diversas, maior prestixio e que non se corresponden coas da localidade. 
nio Fernandj de Rodero distintas persoas da contorna; os outros topónimos implicados refírense aos concellos veciños de Paradela, O Incio e Sarria. Contribúen a este criterio de localización os lugares consignados na relación de testemuñas.

(d) Cando os outros criteiros fallan, consideramos o lugar da colección documental. Por esta razón, chamamos provisoriamente 1250-Montederramo ao documento de Petrus Martini, xa que non puidemos localizar con seguridade os topónimos alí mencionados.

3. Aos moitos problemas da correcta datación dos documentos, comentados con maior coñecemento en varios capítulos deste mesmo volume, únese a dificultade aínda maior de localizar e ordenar cronoloxicamente as variantes contidas neles. Isto é, se dunha banda cómpre precisar a data do documento, tendo en conta se é un orixinal, unha copia ou traslado, ou unha falsificación, doutra cómpre ter presente que determinados estilos e rexistros favorecen a emerxencia de formas gramaticais e léxicas marcadas como anticuadas ou como innovadoras.

Nas obras literarias súmanse os problemas derivados da confección da obra e da transmisión textual. Por facermos só algúns comentarios significativos, que non nos desvíen do noso obxectivo principal, diremos que é previsible que unha crónica, que por natureza non procura a orixinalidade, aproveite textos preexistentes na mesma lingua ou traducións, en todo caso fontes que poden estar marcando a nova obra con características cronolóxicas máis antigas. Retomando como exemplo o comentario sobre o carácter facticio de Miragres de Santiago, é dificultoso datarmos as formas lingüísticas das distintas partes, porque no estado actual da investigación descoñecemos a procedencia e datación dos seus fragmentos; chama a atención, por exemplo, que en tres fascículos diferentes se rexistre a forma primitiva vosco (fasc. $1^{\circ}$, convosco [1] / vosco [1]; fasc. $4^{\circ}, \operatorname{vosco}[1]$; fasc. $5^{\circ}, \operatorname{convosco}[4] / \operatorname{vosco}[1]$ ), que nesa altura (fins do século XIv, inicios do Xv) non está xa aboada por outros testemuños e que por iso atribuímos ou a unha vontade estilística de certa grandilocuencia ou, con maior probabilidade, a factores de transmisión textual (Álvarez 2004). Finalmente, unha vez máis, non podemos deixar de referirnos á tan alegada intervención uniformadora dos colectores sobre o corpus lírico, que non sabemos ata que punto afectou a variantes diacrónicas.

4. Non poucos estudos sobre a lingua medieval (gramáticas históricas incluídas) descoidan a información cronolóxica e ofrecen a falsa aparencia dunha lingua uniforme nun corte sincrónico de tres séculos, o que a todas luces é imposible. Emporiso, a ninguén se lle escapa que, nunha empresa coma a nosa, a cronoloxía é fundamental. En calquera aproximación minu- 
ciosa á lingua medieval compróbase que a variación diacrónica e a variación dialectal están estreita e invariablemente combinadas: variantes diatópicas que remontan a distintas evolucións constitutivas a partir do latín ou evolucións romances particulares dunha variedade lingüística (territorial, social, etc.) difúndense e gañan falantes e territorio co paso do tempo; valla como ilustración o mapa de sigues/segues presentado en Álvarez / Xove (2005).

Tomemos como mostra os datos dos nomes dos meses, un campo hoxe fortemente castelanizado, para estudarmos a distribución das formas en -bro

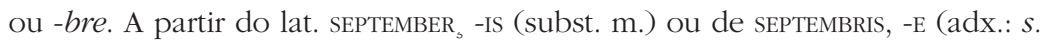
mensis) agárdase en principio o final en -e xeral nas linguas románicas, e a solución en -o explícase por alteración de - e e por iso é cronoloxicamente posterior. Se ollamos para a distribución actual vemos un amplísimo dominio territorial da terminación -bre, con frecuencia ligada a outros trazos que delatan a pegada castelá; as formas sen ditongo tipo setembre son escasas e están esparexidas nun amplo territorio, difícil de precisar, acaso cunha concentración algo maior nunha franxa central polo leste da Coruña e Pontevedra e o oeste de Ourense, e as formas tipo setembro son raras e tamén sen distribución clara (os mapas con todas as formas actuais pódense consultar en $A L G a$ [IV 133-136], e acompañados de estudo en Aira / Martínez 2002).

A situación é moi distinta na lingua medieval, pois, se ben a cartografía non mostra unha distribución dialectal en áreas complementarias (mapa $\mathrm{n}^{\circ}$ 1: setembre / setembro ${ }^{6}$ ), si ilustra un proceso de substitución que se comeza a operar desde moi cedo. No mapa advírtese que no século xiII hai un claro predominio de -bro, evidenciado na maior presenza de cadrados negros, e nalgunhas rexións esta forma mantense sen concorrencia aínda durante o século XIv; por tanto, a mencionada evolución inicial $-e>-o$ deuse con anterioridade ao cultivo do galego como lingua escrita. No mapa percíbese tamén que logo -bre gaña paseniñamente espazo, pois sempre que concorren ambas as variantes a forma con - $e$ final é contemporánea de -o ou máis tardía, con presión maior e máis temperá nunhas zonas ca noutras (como tendencia, pódese dicir que hai máis -bre no centro-norte ca no sur). En suma, nunhas áreas -bre é a forma autóctona, invariable no tempo, e noutras é o resultado dun dobre proceso substitutorio $(-e \rightarrow-o \rightarrow-e)$.

6. Para non facer unha interpretación errónea dos datos, cómpre ter presente que o mapa é orientativo e está simplificado en extremo: ademais de considerarmos só dous períodos dun século enteiro, en cada lugar rexistramos só presenza/ausencia, sen termos en conta o número de ocorrencias. Os datos corresponden só ao nome do noveno mes: aínda que se poida inferir que a presenza de -bro en setembro implica por igual aos catro últimos meses do ano, no mapa non se misturan os datos dos tres seguintes. 
Setembro (séc. XIII-XIV, fonte: TMILG)

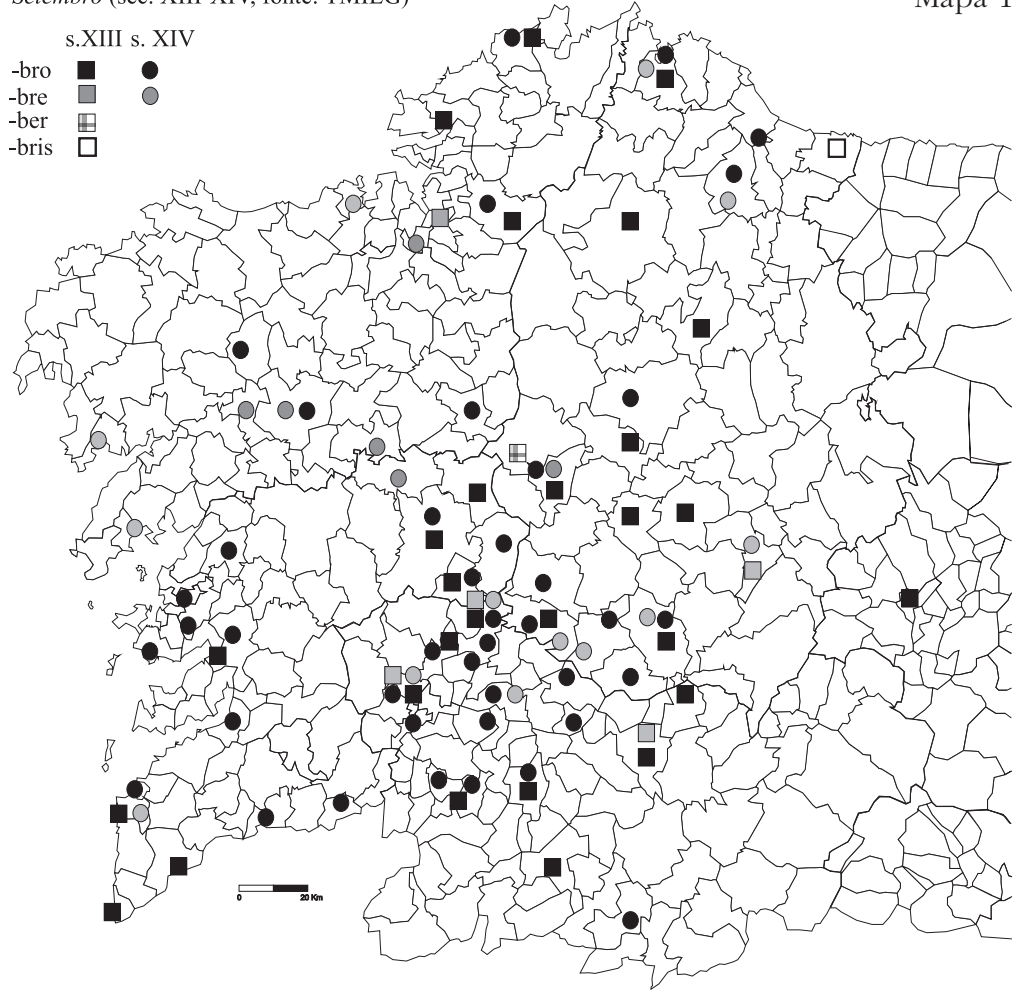

Mapa 1

Se volvemos a ollada aos datos do período de emerxencia obxecto desta contribución comprobamos, en efecto, a variación -bro/-bre existente desde as orixes da escrita (mapa $\mathrm{n}^{\circ}$ 2). A carón de <setẽbre, setembre> [c1253-Ombre], setembre [1258-Oseira] e <dezenbre > [1240-Corgo], tópase con equivalentes latinos ou latinizantes que forman parte do formulario, do tipo setembris [1259-Ribadeo], <septembris, septẽbris, se \p/te[m]bris > [1231-Melón/Borbén, 1240-Corgo, 1255-Melón/Mondariz], <octobris> [1243-Lourenzá], <nouẽbris, nouenbris $>$ [1247-Maceda, 1257-Pallares] e <decenbris $>$ [1251-Monterrei] ou do tipo <octuber> [1260-Ribadavia], <decẽber> [1257-Meira, 1258-Oseira $]^{7}$.

7. Non é infrecuente que a data se dea en latín, máis ou menos correcto, "Facta karta V calendas de.cenbris, era $\mathrm{M}^{a} \mathrm{CC}^{\mathrm{a}} \mathrm{LXXXVIIIJ}^{\mathrm{a}}{ }$. Damos estas formas a título de exemplo e por apareceren nos textos estudados por nós, como é obvio sen pretensión de exahustividade no conxunto documental do período. Doutra banda, debe terse en conta que en moitos casos a diferenza formal entre -ber ou -bre é debida ao criterio do editor no desenvolvemento da abreviatura. 
Fronte a elas, a vogal -o faise explícita en <setembro, setembro, septẽbro > [1254-Vilafranca, 1255-Maceda, 1257-Montederramo, 1258-Monterroso], setenbro [1257-Trasancos, 1259-Paradela], <outubro> [1260-Pruzos], <dezẽbro> [1255-Melón/Mondariz, 1255-Sobroso] $]^{8}$. Os datos son escasos pero non contradín o mapa anterior, cun arco temporal máis amplo, pois o certo é que os primeiros rexistros romances son, basicamente, de -bro, que compite sobre todo con formas latinas; emporiso, as formas en -o faltan nun gran espazo nororiental. As formas en -bre son escasas, quizais porque a variante está apagada baixo -bris e -ber e son de orientación setentrional.



8. Damos só datos anteriores a 1260. Os que non proceden dos textos sobre os que se centra este traballo son tomados de TMILG, e alí remitimos. Cómpre advertir de que moitas das edicións contidas neste Tesouro non marcan graficamente os desenvolvementos de abreviaturas. 
Así pois, contra o pronóstico, nesta marxe occidental da Romania a solución -bro, a máis afastada da latina, é xa a predominante desde períodos moi recuados, pero a variante -bre, máis primitiva, retoma máis tarde o espazo e acaba por facerse predominante na lingua falada; a solución normativa moderna, a favor de -bro, impulsa un cambio en sentido contrario. Non é infrecuente este ascenso e descenso das variantes lingüísticas sobre o territorio, que lembran os movementos da marea: o testemuño nun lugar dado nun momento dado non implica a súa permanencia no tempo, e esta evidencia obriga a consignar sempre as coordenadas de tempo xunto ás de espazo.

5. En efecto, a análise da distribución dialectal na lingua medieval mostra adoito que a evolución diacrónica non se produce de forma nin tan simple nin tan lineal como podería conxecturarse a primeira vista. Mostra, asemade, que hipóteses explicativas simples e apriorísticas, des que se colocan os datos nas coordenadas espaciais e temporais axeitadas, axiña se revelan inapropiadas para dar cabal explicación dos complexos procesos que seguen os cambios lingüísticos e a súa difusión. Imos exemplificalo coas voces taleiga e agusto, presentes nos documentos estudados.

Nesta monza de textos anteriores a 1260 atopamos as seguintes variantes formais antecedentes da forma tega / $\mathrm{k} /$, medida de capacidade para gran, castañas e sal: taleyga en 1233-Melón/Covelo, teega tééga (8v) e teyga (3v) nun documento copiado no tombo de Caaveiro (c1253-Ombre), taega (2v) en 1243-Lourenzá e talega neste último documento e mais en 1244-Veiga (4v) e 1251-Monterrei; á vista destes datos, pódese aceptar que <tla> representa taleyga en 1233-Melón/Covelo e que <t> é abreviatura de teega $\sim$ teyga noutro documento de Caaveiro (c1260) ${ }^{9}$. Outras solucións fonéticas ou gráficas medievais son taleiga, teiga, teeiga, teeyga e tega.

Dúas das variantes presentan un - $l$ - intervocálico desaparecido nos descendentes tego e tega do galego moderno (do ár. taclîqa 'bolsa, saco', Corominas: S.v. TALEGA). A forma talega do arabismo podería ser préstamo a través do castelán, pero esta doada explicación non é válida para taleiga; non se descarta que ambas e dúas poidan ser nalgúns casos variantes gráficas,

9. Chamamos a atención sobre un feito obvio que non sempre se ten presente: as abreviaturas poden ser xerais, pero o seu desenvolvemento non. Unha mesma convención gráfica pode representar variantes lingüísticas diferentes segundo a época e o territorio: $<\mathrm{t}>$ terá que desenvolverse como teega, taleiga, teyga, etc., segundo se estableza en cada caso a partir de informacións complementarias. Polo mesmo, a abreviatura pode transmitirse como un símbolo e non ter traslado letra a letra á forma con que se desenvolve; dito doutro xeito, a forma que dá lugar a $<$ tla $>$ ten $<\mathrm{l}>$ na forma plena, pero cando se difunde esta convención pode pasar a representar igualmente a teega, teiga, tega... 


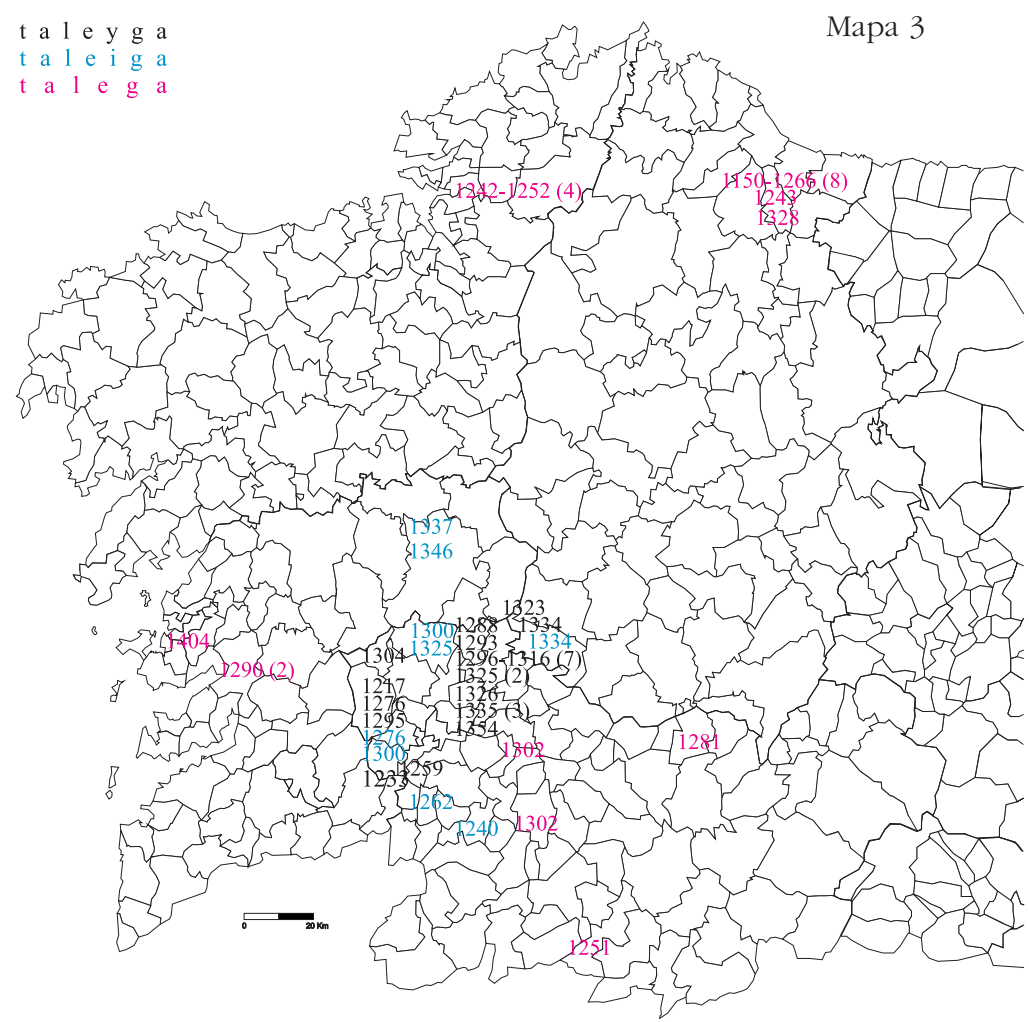

cunha grafía <e> por /ei/, coma a que se comproba en <Cerdera> por Cerdeira [1255-Trives] ou <ianero> por ianeiro [1251-Monterrei]. A primeira hipótese foi que a presenza do $<\mathrm{l}>$ no préstamo, directo ou a través do castelán, se podería explicar como variante conservadora puramente gráfica ${ }^{10}$,

10. A mesma interpretación parece darlle Martín Sarmiento, que ao rexistrar tega comenta: “Medida de áridos. Úsase en Orense, etc., y se usaba en Pontevedra; hoy creo se usa sólo para medida de castañas. Su origen es el mismo de la talega, pues en instrumentos latinos del Poyo (de quinientos años) hallé, per taleigam de Morracio, per taleigam de Ponteveteri, etc., en los gallegos antiguos se llama teeiga, y hoy tega" (CVFG: 267). E noutro lugar engade: "Año de 1221. Ego Nunus Petri Maledolatus miles et uxor mea Eldara Fernandi [...] VI modios de pane per taleigam de Ponte veteri. (Aquí se ve el origen de los Maldonados y de la tega (Poyo.)" (Sarmiento 1975: 139). Unha visita a CODOLGa permite comprobar que taleiga supón o 30,15\% das ocorrencias nos textos latino-galaicos dos séculos XI-XIII, con distintas cronoloxías e localizacións, e talega o 60,29\%; o resto é para variantes se $-l$-, presentes desde moi cedo na documentación de Sobrado. 


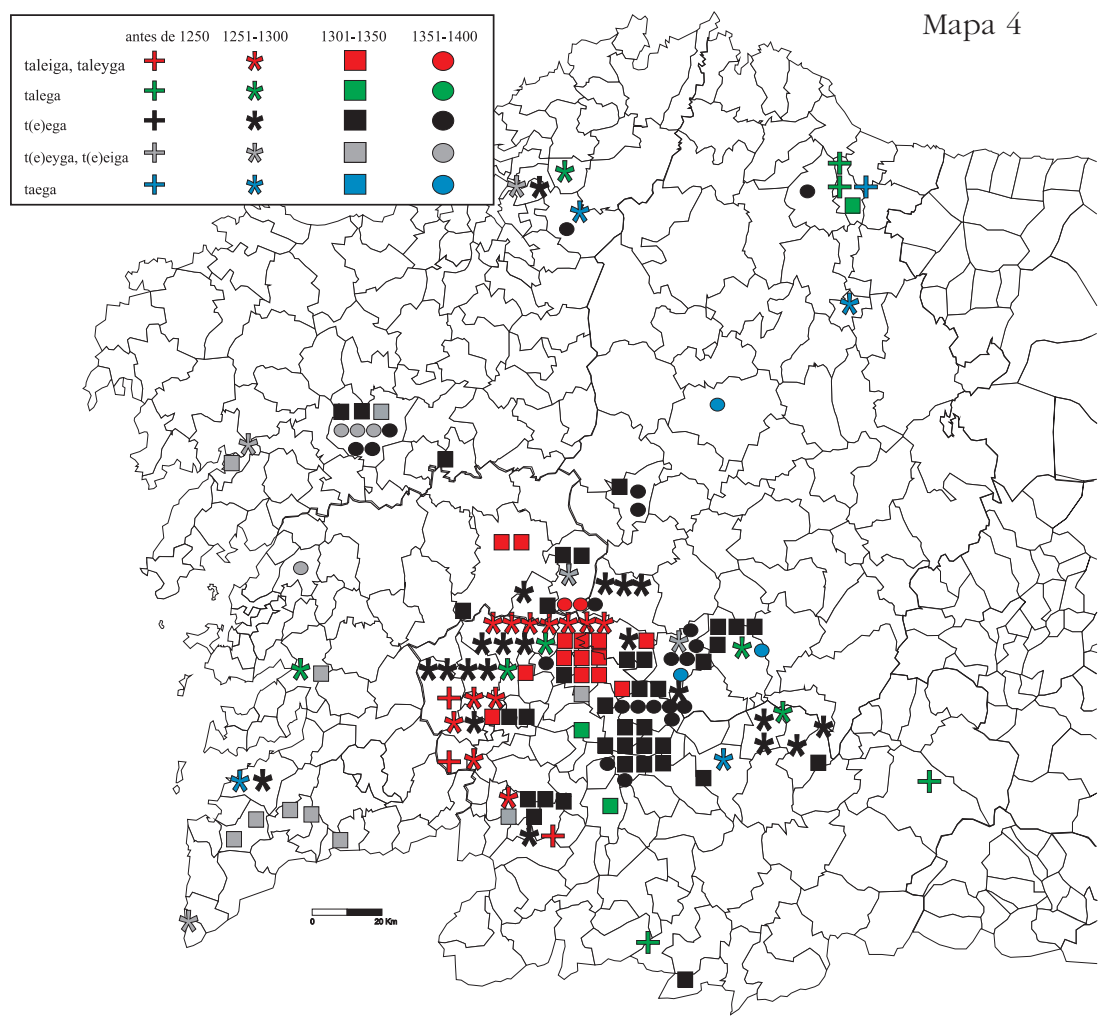

pero a cartografía e cronoloxía das formas con $<1>$ rexistradas en TMILG fixéronnos desbotar axiña esta idea, pois taleyga $\sim$ taleiga concéntranse nunha área xeográfica central, a ambos os lados do curso medio do Miño ao sur de Chantada, cunha dilatada presenza ao longo dos séculos XIII e XIV nas coleccións documentais desta bisbarra ("área taleiga"); a forma talega, por vez súa, máis esporádica, espállase na contorna desa área e en lugares moi afastados (mapa $\mathrm{n}^{\circ}$ 3: taleiga) ${ }^{11}$. Obsérvese que o rexistro de taleiga en Melón, neste feixiño de documentos temperáns, encádrase dentro da área mencionada, e que por contra o teega teyga de Ombre (Pontedeume) está fóra

11. A cartografía está feita a partir dos datos de TMILG en novembro de 2005. Obviamente, nunha elaboración máis atenta cumpriría a revisión dos documentos á luz das cautelas antes mencionadas, moi en particular a comprobación de se se trata de documentos orixinais, copias ou traslados, e mais de se algunhas destas formas son desenvolvementos de abreviaturas. 
dela. Do dito non se debe desprender que taleiga se circunscribise só ao territorio que nos deseñan os datos achegados, pois está ben aboada en portugués ata a época contemporánea e Sarmiento constata a súa presenza en textos pontevedreses antigos (cf. nota 10$)^{12}$; a localización galega na conca do Miño convida a comprobar ata que punto a vía fluvial puido xogar un papel na penetración e implantación desta variante. En galego taleiga desapareceu como denominación da medida, aínda que se mantivo co significado inicial de 'saco', segundo consta indirectamente en Sarmiento (taleigueiro) e de forma expresa nos lexicógrafos posteriores ${ }^{13}$.

Se observamos tamén o mapa que recolle as outras variantes (mapa $\mathrm{n}^{\circ} 4$ : tega), vemos indicios dun proceso de cambio que habería que confirmar con maior número de fontes: (a) na área "taleiga" as primeiras documentacións (primeira metade do século XIII) son de taleiga e fóra dese dominio son de teega, taega e teiga, e en menor medida de talega (variante ou non de taleiga); (b) na segunda metade do séc. XIII, xa con maior abundancia de rexistros, observamos na área "taleiga" a forte concorrencia de teega e, en segundo lugar, de tega e talega; (c) a situación é similar na primeira metade do séc. xIV, coa particularidade de que taleiga reduce o seu dominio ante teega, tega e teiga; (d) finalmente, na segunda metade do séc. XIV só atopamos taleiga en Oseira. ¿Que pasou a partir dese momento?: na mesma base de datos comprobamos que taleyga taleiga desaparece dos seus documentos durante o séc. XIV (o último rexistro é de taleiga en 1373 Oseira), e que as

12. En portugués moderno, taleiga defínese como antiga medida para áridos sen adscrición rexional ("antiga medida para azeite [dois cântaros] e cereais [quatro alqueires]", en tanto que teiga se trata como rexionalismo miñoto ("três alqueires acogulados de sal") (Houaiss: ss.vv.); ademais, só a primeira ten unha familia de palabras derivadas ao seu arredor: taleiga, taleigada talagada, taleigo / teiga. João Saramago, coa xenerosidade habitual nel, infórmame de que o equipo do atlas lingüístico de Portugal non recolleu a voz teiga como medida en ningún lugar, aínda que hai testemuños fiables de que en Caminha é unha medida de sal equivalente a 50 litros; o mesmo equipo recolleu taleigo en diversos puntos como 'saco para transportar o cereal ou a fariña, entre a casa e o muíño', coa variante taleiga en dúas localidades dos Açores.

13. "Taleigueiro, toleiron, manteigueiro, lareiro, lampantin, lavérco, laranxo, maloután, etc., son nombres despreciativos de hombres toscos, grandes, rústicos, mal hechos, etc." (CVFG: 319). Cf. DD: S.v. TAleIGa, 'saco pequeno, e en particular bulsa para o diñeiro', 'bulsa en que comen as cabalerías', 'saco que levan os mariñeiros coas súas cousas ao mar' e, figuradamente, 'mil pesos en prata'; s.v. TALEIGo, 'saco máis estreito e longo cá taleiga, especialmente para o diñeiro'; s.v. TAlega, 'especie de bitillo que impide comer ao gando', 'zurrón'. Os datos do ALGa (cuestión 879: 'medidas para gran') mostran que todas estas variantes medievais concorreron en tega, que é tipicamente ourensá, se exceptuamos a franxa máis occidental da provincia, e penetra no sur de Lugo e nas terras de Dozón e Camba pontevedresas; ademais, o masc. tego é nome de medida nun territorio en parte lucense en parte mindoniense, onde debuxa unha área oriental compacta. Falamos de descendentes da voz estudada, sen entrarmos no significado e equivalencia de medida. No resto do territorio impúxose a forma ferrado, que na Galicia occidental substituíu por completo estoutras variantes medievais. 
variantes teega e tega se acaban impoñendo sobre as cada vez máis minoritarias teyga teiga e taega (últimos rexistros teyga en 1422-Pontevedra e taega 1449-Pantón), á vez que amplían o seu dominio oriental.

Á vista de agusto, como nome do mes (1228-Allariz, 1233-Melón/Covelo), e das "caendas agustas" (1255-Portomarín), podemos pensar nunha grafía latinizante que lembra a forma latina AUGUSTU. En efecto, os textos romances medievais mostran con frecuencia grafías e solucións latinas, que se explican ou ben porque a lingua de cultura serve de substrato gráfico ou ben porque hai un propósito latinizante; ora ben, non todas as variantes que coinciden coa forma latina son solucións gráficas ou morfolóxicas explicables por esa vía. Consultando a base TMILG atopamos outros rexistros na mesma área xeográfica, nun tempo algo alargado (1262 e 1266 Oseira, 1279 Asma, 1391 Ferreira de Pantón); se se trata en efecto dunha grafía seguidora da latina, sorprende que non xurdise en ningún momento dese grande arco temporal noutros lugares. A mesma persistencia no tempo indica que non se trata dun trazo atribuíble nin a un escritorio nin a unha moda circunstancial. Aínda que son moi poucos datos para tirarmos conclusións diatópicas, non sobra lembrar que Melón forma parte dunha área suroccidental que se caracteriza por magusto fronte ao xeral magosto ${ }^{14}$.

6. Dificulta a tarefa a existencia de distintas solucións gráficas, mais ou menos artelladas en modelos de certa continuidade, e mesmo de distintas tradicións escriptolóxicas. Non habendo unha norma única, é preciso un fino traballo de filólogo para descubrir ata que punto as diverxencias se deben a distintas opcións ortográficas para representar a mesma secuencia fónica ou, por contra, a homografía agocha unha variación real. Vexamos só estes dous fragmentos tomados de Friol (c1242), no primeiro salientamos con trazo groso as vogais da serie anterior e no segundo as da serie posterior:

Pidru Gil iurado is prigõtado dici qui viu tíjr ad Pi- $\left.\right|^{2}$ dru Fernãdit et partir a villa di Giay et tijir ad uos $\left.\right|^{3}$ di Ffernã Diat sou padre $\tilde{\mathbf{i}}$ isa villa. Is pregõtado quanta tií- $\left.\right|^{4}$ na $\tilde{\mathbf{i}}$ isa villa di Giãy, dici qui ad VIIIJ ${ }^{a}$ disa villa di $\left.\right|^{5}$ Giãy et tina Pidru Fernãdit $\tilde{\mathbf{i}}$ iur et $\tilde{\mathbf{i}}$ mau aquila qui $\left.\right|^{6}$ partirã et mays nõ. Is prigõtado do tepo, respõdiu qui nõ sabe. $\left.\right|^{7}$ Is prigõtado de hora, dici qui nõ sabe. Is prigõtado quin erã presen- $\left.\right|^{8}$ tes, dici qui nõ sabe.

14. A similitude non semella casual. Corominas (s.v. AGOSTO) aventura unha relación etimolóxica entre ambas as voces . 
[Io]han Pirit iscudeyro de Felgoso, filio di Pidru F[e]rnã $\left.\right|^{2}$ Uermuit Reuoliõ iurou, $e t$ is prigõtado, dici qui viu tijr ad Pi- $\left.\right|^{3}$ dru Fernãdit $e t$ ad sou filio ĩ iur et ĩ mau ad VIIIJ' da $\left.\right|^{4}$ [v]ila tuda de Giay pur si et pur sous tudures et leuar $\left.\right|^{5}$ [in]de a renda et inde padro

Da análise destes dous fragmentos dedúcese que o grafema $<\mathrm{i}>$, en función vocálica, representa un abano fónico que recobre o $\operatorname{arco} / \mathrm{i}$ - e/, en posición tónica ou átona; en cambio, o grafema $<\mathrm{e}>$ representa normalmente /ع/, tónico ou átono (subliñados no texto), e só minoritariamente /e/ átono. Destacamos, con todo, a forma quin: se se trata do relativo quen, sorprende a opción con vogal pechada en lugar de / $/ \varepsilon /$, polo que habería que estudala con máis rigor xunto coas restantes vogais trabadas por nasal (cf. quin nos Foros de Castelo Rodrigo [1280-1290, cfr. Cintra 1959] e en 1315 Orcellón [cfr. Maia 1986: 694-695]); de todos os xeitos, cremos máis probable que se trate da elisión da vogal inicial do pronome en e que haxa que ler qui'(e)n. Canto á serie posterior, atopamos /o/ grafado como $<\mathrm{u}$, o $>$, en ambas as posicións, e /u/ como <u>, aga no contexto de núcleo con coda nasal, <õ > (prigõtado, coma padrô). Así pois, testemuños como li(s), respondiu ou aquisto, dentro deste sistema gráfico, non deben ser tomados como rexistro de dativos en - $i$, de P3 do Indicativo Pretérito de verbos da CII en /iu/ ou de demostrativos autónomos con /i/ nas terras de Sobrado en época temperá, senón como grafías equivalentes a le(s), respondeu e aquesto, as formas esperables neste territorio ${ }^{15}$; pola mesma, non podemos afirmar se en tijr temos ou non o primeiro testemuño dun tir que sabemos existe hoxe non lonxe deste lugar, nin se baixo a forma $<\mathrm{dy}>$ do SPte de dar hai unha lectura $/ \mathrm{d} / \mathrm{ou} / \mathrm{di} /$, , como en "e traslado de ueruo a ueruo que non tolly nen a dy per mandado de don Afonso Rodrigues" (1294, CDVilarDonas: 271). Este tipo de solucións gráficas —que expón no capítulo correspondente Ana María Martins, como características do que ela chama "escrita primitiva portuguesa conservadora" - repítense noutros textos deste período emerxente, coma o de 1247-Páramo, próximo xeograficamente do anterior:

15. As tres formas teñen distribución dialectal no galego medieval: as formas do dativo en - $i$ son típicas do galego suroccidental, as formas de Indicativo Pretérito da CII do occidente coruñés e os demostrativos autónomos con / i / de dúas áreas, unha tudense e outra mindoniense occidental. Noutro tempo e lugar (Álvarez / Xove 1998: 44), interpretamos testemuños de isto e aquisto en Sobrado 1300 como antigo límite meridional da área mindoniense de /i/ nos demostrativos neutros; esta posibilidade dun sistema gráfico diferente obríganos a volver sobre os textos para confirmalo ou corrixilo. 
quanta | uoz a_mj̃ pert̃̃ze por mea cabiza ĩ Uilar Moystero. Et eu outrusi, Adã Martiz ĩsimbla | cũ meos irmaos, Valasco Martiz $e$ Guillelmj Martiz, outorgamos a uós, dõ Monio Fernãdj, | e a_uossa uoz quanto irdamento quanta uoz a_nós pertĩjze ĩ Uilar Moystero.

O traballo con concordancias, sen referir os rexistros individuais ás coordenadas en que se estea cada texto, pode inducir a erros deste tipo ${ }^{16}$.

Hai dificultades que son circunstanciais e que, por tanto, deberían ou poderían desaparecer en canto mudasen as condicións. Referímonos, nomeadamente, aos tipos de edición existentes e mais á dubidosa fiabilidade de moitas delas. Obsérvese que situamos o problema nunha dobre vertente: dunha banda, obras rigorosas desde un punto de vista metodolóxico poden responder a un tipo de edición que prescinde de marcar de maneira diferenciada trazos grafemáticos ou de disposición en páxina que son interesantes para a investigación lingüística; doutra, atopamos con maior frecuencia da debida edicións descoidadas ou feitas por persoas inexpertas que ofrecen lecturas pouco fiables.

7. En calquera momento histórico conviven variantes lingüísticas con distribución xeográfica, social ou estilística, ademais de evidentes arcaísmos. Separar unhas e outras non é doado, nin sequera respecto da lingua actual, sobre a que existe un coñecemento, unha proximidade e unha posibilidade de consulta que non temos para a Idade Media. Formas que son características dunha zona poden ser variantes doutro tipo noutra. É traballo tamén do filólogo tentar distinguilas sen caer na trampa de pensar que todas as variantes son (só) diatópicas.

O estudo diacrónico do pronome autónomo elo (Álvarez 2003-2006) permitiunos concluír que esta é unha forma autóctona que se documenta desde os primeiros tempos da tradición tabeliónica en galego, pero a mediados do séc. XIV iniciou un ascenso que se fixo máis evidente durante o séc. XV, e só neste momento de máximo apoxeo logrou romper ocasionalmente a restrición sintáctica que lle impedía funcionar como suxeito; comprobamos, ademais, que os demostrativos autónomos con $<i>$ e elo pertencen a variedades distintas e non adoitan concorrer no mesmo texto (nin son habituais na

16. Son moitos os exemplos que se poderían poñer nesta secuencia argumental. Valla estoutro testemuño da área de Ribadavia (Tato 2004:771): "E mandu a mía uina de su a eclesia de Francelu e a do Rigeiru a meu tiu [...]. E mando a Goncaluu Iohanes e a seus quirmauuns hu foru que hec cun ilis, e o qui me fat Iohán Arias, zapateiru" (1260, Testamento de Estevo Pérez), onde o uso reiterado de $<\mathrm{u}>$ por $/ \mathrm{o} / \mathrm{e}<\mathrm{i}>$ por /e/ non permite, por exemplo, considerar testemuñado o pronome $i l$, que se revelará máis adiante como variante tipicamente auriense. 
mesma área). A cronoloxía das formas e esta incompatibilidade invalida, na nosa opinión, as hipóteses xeralmente asumidas para explicar por que elo non evolucionou a ilo (consonte isto, iso, aquilo); a nosa análise dos datos levounos a concluír que se conxugaron diversos factores, entre os que destacamos de maneira fundamental a analoxía, sobre todo con aquelo aquello. Pero, sobre todo e para o que neste momento nos interesa, levounos a concluír que a tipoloxía dos textos, a súa estrutura interna e o carácter formulario que caracteriza algúns estilos foron determinantes para o ascenso dunhas formas sobre outras.

8. Ata agora fomos enunciando os problemas máis importantes que non todos- con que nos enfrontamos ao facermos aproximacións dialectais á lingua medieval. Ser conscientes da magnitude e complexidade das dificultades é a mellor maneira de prepararse para facer a travesía con algunhas garantías de éxito. A pesar de todas as pexas, cremos firmemente na posibilidade de estudo e sistematización da variación diatópica da lingua galega medieval, como xa tentamos mostrar con feitos noutras ocasións.

Animamos unha dialectoloxía histórica e diacrónica que, neste nivel de desenvolvemento dos estudos, ten máis viabilidade enfocada á análise e descrición de fenómenos e formas particulares ca ao establecemento de dialectos diferenciados. A análise de distintos trazos na lingua medieval lévanos a concluír que a distribución espacial e a evolución cronolóxica debe ser establecida mapa a mapa, sen moitas posibilidades de extrapolación. A modo de exemplo, e para non nos estendermos na advertencia, remitimos de novo a un noso traballo recente a propósito da alternancia vocálica en verbos da CIII (Álvarez / Xove 2005): о mapa de sigues-sigue-siguen/segues-segue-seguen ofrece importante información sobre a cronoloxía da evolución diatópica da morfoloxía deste verbo en particular, pero como se mostra naquel lugar estas conclusións non atanguen por igual aos outros verbos que comparten hoxe este modelo conxugacional de tripla alternancia.

Para poder elaborar esa descrición dialectal cómpre considerar moitos datos apoiándose mutuamente en estilos similares, con distintos autores, continuándose no tempo, nun mesmo territorio. Se os rexistros galegos do dativo $l i$ se concentran en número significativo durante a segunda metade do século XIII en documentos producidos na parte suroccidental da provincia de Pontevedra, temos que concluír que é un trazo dialectal, o que explica a presenza na tradución da Crónica Geral, tudense (Álvarez 1994, Álvarez / Xove 1998). Se todos os rexistros do pronome outrẽ $\sim$ outre $\sim$ outri 'outra persoa' (port. outrem) se concentran nunha área meridional (cando menos, desde a conca do Sil á costa tudense), reiterándose da man de distintos escribentes entre a segunda metade do séc. XIII e o segundo terzo do XIV, te- 
mos que concluír igualmente que este era daquela un trazo dialectal desta zona (Álvarez / Xove 1998); o mesmo ocorre cos testemuños de autro/autra, que, outrora coma hoxe, caracterizan textos orixinados no territorio lucuauriense e non se rexistran en ningún outro lugar.

Por iso, o escaso número de textos e, xa que logo, de rexistros engade maior dificultade á misión encomendada polos organizadores do simposio Na nosa lyngoage galega e deste volume. De todos os xeitos, cremos que este achegamento permite tirar conclusións interesantes e suxerir liñas de traballo moi atractivas, como tentaremos mostrar no capítulo seguinte.

\section{Os trazos dialectais dos teXtos DO PERÍOdo DE EMERXENCIA}

A análise dos primeiros textos desde o punto de vista da variación lingüística non é doada porque se incumpren os principios antes mencionados: carecemos dos tales moitos datos apoiándose mutuamente en estilos similares, con distintos autores, continuándose no tempo e nun mesmo territorio sobre os que establecermos un deseño minimamente aceptable da arquitectura do idioma nesa altura. Ora ben, iso non impide facer algunhas aproximacións e mesmo, coas debidas cautelas, tirar conclusións de interese.

Do que se di a seguir non debe inferirse que postulamos unha estrita continuidade histórica entre variantes nos mesmos territorios. Todo o contrario: como xa indicamos noutros lugares, coidamos que a historia foi moito menos lineal do que se pode crer a primeira vista e que con frecuencia as distintas variantes pasaron por épocas de auxe e decadencia, con abalos e devalos sobre o territorio. Ora ben, esta aproximación dialectal aos primeiros textos pon de relevo, de forma moi evidente, a antigüidade dun bo monllo de trazos que seguen tendo distribución dialectal na actualidade, pois hai que remontalos a unha época anterior á emerxencia da lingua escrita.

Son varias as conclusións que queremos remarcar con exemplos tirados dos textos anteriores a 1260, que organizaremos en tres liñas expositivas. Algúns fenómenos foron xa comentados ao longo da exposición anterior, polo que agora engadiremos algúns outros exemplos significativos.

1. O primeiro feito salientable é que, naqueles casos en que xa posuímos información contrastada sobre a variación medieval, estes textos cumpren as nosas expectativas:

(a) En certos contextos sintagmáticos atopamos a variante do identificador autr- en 1255-Montederramo ("et non autre") e en 1255-Portomarín ("ante ca autro home ne ca autra moler"), e non fóra da área lucuauriense. 
(b) Nalgúns casos o nivel de coñecemento só permite facermos conxecturas. Por exemplo, no foro de Castro Caldelas atopamos a palabra cóóma cóómia (variantes de coima, 'multa, paga compensatoria') e unha busca en TMILG permítenos documentar esta variante, con pequenas diverxencias formais, nunha área SW, entre a liña Oseira-Terra de Aguiar-Allariz e a costa tudense ${ }^{17}$.

(c) A partir de lat. DEB̆TA espérase en galego débeda, que é efectivamente a forma maioritaria nos textos. Ora ben, a cartografía mostra que as formas en -ida (dévida ou dívida, con variantes gráficas), con non ser moitas, están concentradas nunha área xeográfica suroccidental (tudense en sentido amplo), diferenciada con frecuencia na cartografía dos fenómenos medievais; neste caso advírtese, ademais, que con estes datos as formas distribúense en dúas áreas contiguas complementarias. Baixo a forma deuida atopámola na tradución da Crónica Geral (ms. 8817, tudense), en tanto que o manuscrito $\mathrm{A}_{1}$, máis tardío e doutra área xeográfica, mostra déueda. Consonte o exposto, nos textos alborais analizados para esta ocasión atopamos deueda en 1228-Allariz (5v) e 1255-Maceda.

(d) No Subxuntivo Presente do verbo dar, Maia salienta o predominio de de- en todo o territorio e en todo o período que estuda, mais tamén que as formas con tema dia- ou dea- só se dan en documentos galegos, nomeadamente lugueses e ourensáns, de onde infire que na Galicia oriental convivían as dúas flexións do subxuntivo, de- e \{dia-, dea-\}; indica ademais que esta área prolonga a área lingüística asturiana e leonesa, onde tamén conviven estas opcións (1986: 778-779).

Os datos de TMILG permiten facer unha aproximación máis matizada. Sen cuestionar o predominio xeral de $d e$-, pódese afirmar que dia- ten un amplo territorio oriental onde é moi característica desde os primeiros tempos, e de feito Maia non dá exemplos doutra opción para a rexión de Lemos-Caldelas-Montederramo. En cambio dea-, que tamén conta con rexistros esporádicos desde o inicio no centrooriente, vai gañando espazo paseniñamente e ten un grande auxe no séc. $\mathrm{xv}$, disputando o terreo tanto a dia- coma a de-. O mapa actual mostra como dia- reduciu o seu espazo primitivo, pois xa non se re-

17. Os rexistros son poucos e case todos do séc. XIII. Ademais dos do foro de Caldelas, cooma en 1283-Nogueiroá (Terra de Aguiar) e 1332-Oseira, cóóma en 1289-Tui e 1296-Baiona, tooma en 1283-Tui (lectura defectuosa por cooma?). Houaiss (s.v.: corma) dá como variantes documentadas en port. antigo 1255 coomia, 1262 cóógma, 1262 cooyma, séc. XIII choomba, séc. XIII comhaa, 1331 cooimha. 
colle nesa gran rexión lucuauriense vertebrada polo Sil e o curso medio do Miño, onde tiña unha gran presenza antigamente; mostra tamén como nesta área e en todo o occidente triunfou dea-, sen deixar vestixios da forma de-, outrora maioritaria ( $A L G a$ : I 230).

Os nosos textos testemuñan a variación descrita xa desde os inicios. Atopamos dia (e $d y$ ) en 1228-Allariz e diades en 1255-Trives, no cerne da área de dia-, xunto a un uso xeneralizado de de-, que inclúe textos da veciñanza: dé (c1253-Ombre), dés (1233-Melón/Covelo), dedes (1231 e 1233-Melón, 1244-Veiga, 1250-Montederramo), dẽ $\sim$ dem (1244-Veiga, c1253-Ombre).

(e) Como xa se dixo, as formas con /i/ tónico nos demostrativos autónomos teñen carácter dialectal na época medieval, cun territorio pouco máis amplo có que ocupan actualmente (Álvarez / Xove 1998: 43-45). $\mathrm{Na}$ Galicia medieval, as formas con /i/ son características dunha rexión situada no centro-sur da actual provincia de Pontevedra (coas terras ourensás veciñas), que comprende o territorio tudense; con menor frecuencia, tamén se atopan nunha rexión no extremo norte, no mindoniense occidental. En ambas as dúas áreas sempre se documentan, asemade, as formas con /e/, constantes no resto do territorio galego. En concordancia con isto, os textos analizados ofrécennos os seguintes datos de /e/: esto (1228-Allariz, 1252-Veiga, 1254-Vilafranca, 1255-Melón/Mondariz, 1255-Maceda, 1255-Portomarín, 1257-Monfero, 1260-Pruzos), a_esto (1255-Portomarín, c1253-Ombre), desto (1255-Maceda), aqesto (1228-Allariz, 1257-Monfero). Dous dos rexistros de /i/ corresponden a isto na área tudense, confirmando a descrición anterior (1233-Melón/Covelo e 1255-Sobroso); o terceiro (1240-Corgo) non se pode tomar en consideración a estes efectos, porque procede dun texto híbrido en que $<\mathrm{i}>$ representa adoito /e/ (v.g., ista 'esta', inla 'na').

2. Permiten a datación moi temperá de trazos diatópicos e nalgúns casos axudan a fixar unha cronoloxía diferente segundo os territorios.

Está xa presente a variación entre sou $(<\mathrm{suU})$ e a forma analóxica seu, pero en cambio aínda é xeral a presenza de meo meu (< MEU); o paradigma máis achegado á base latina, meu-tou-sou, rexístrase en textos galegos de mediados do séc. xiII e contrasta cos do noroeste portugués no mesmo período (Maia 1986: 676n). Os textos analizados mostran claramente esta diferenza entre meu / sou (c1253-Ombre e c1260-Caaveiro, 1251-Veiga, 1253Ramallosa, 1254-Vilafranca, 1257-Casoio), e a eles poden sumarse os rexistros de sou en 1241-Castañeira, 1257-Pallares e 1260-Cereixo, sen ocorrencias da forma de 1P; en cambio, noutros atopamos xa nestas datas o testemuño da 
forza analóxica, en meu / seu (1228-Allariz, 1243-Lourenzá, 1255-Portomarín, 1259-Montederramo), meo / seu (1255-Sobroso), teu e seu (1255-Trives), seu (1247-Maceda, 1255-Portomarín, 1256-Trives, 1257-Monfero, 1258-Monterroso, 1259-Guntín). Na consulta de TMILG obsérvase como a presenza de sou vai diminuíndo ao longo do período medieval, de forma que no século XV apenas ten rexistros na escrita, todos na Galicia meridional, lonxe das áreas de maior presenza actual de tou-sou e mais da analóxica mou ( $A L G a$ : II 237240). Por contra, a innovación mou apenas tivo traslado á escrita na lingua antiga, pero nos escasos rexistros percíbese unha liña ascendente no tempo (cos datos de TMILG, 1 rexistro de 1270, 8 no séc. XIV, 10 no séc. Xv).

Está tamén xa desde os inicios a variación entre deu e dou no Indicativo Pretérito de dar, curiosamente con maior presenza da forma que se supón analóxica: deo (c1260-Caaveiro), deu (1240-Corgo, c1253-Ombre, 1257-Monfero [3v]) / dou (c1242-Friol [3v], 1260-Cereixo). Hoxe dou ocupa un territorio compacto no NW, constituído pola diocese compostelá e os territorios contiguos, e mais outro máis pequeno no límite oriental; ambos teñen unha expansión, en direccion leste e oeste respectivamente, na forma diu ( $A L G a$ : I 225). Os datos dos primeiros textos non desmenten esa distribución territorial, pois Pontedeume, A Capela, Monfero e Friol sitúanse nos límites da área occidental descrita, O Corgo no corazón da de deu e Vimianzo na de dou. O mesmo ocorre na $1 \mathrm{P}$ deste tempo: xunto á forma maioritaria dei, a lingua medieval coñece unha forma $d i$, que Maia localiza na banda oriental (Lourenzá, Lugo, Quiroga, Caldelas, Allariz); os nosos textos ofrecen xa o testemuño de dey en Friol (c1242) e Caaveiro (c1260) fronte ao de $d j$ en Maceda (1255).

Na 3P dos pretéritos fortes, o galego medieval presenta solucións en -e ( $-i)$, que se continúan en territorio portugués, e solucións en -o, tipicamente galegas; segundo a descrición de Maia (1986: 780) as formas disse e variantes son esporádicas e conviven con disso, pero a abundante información achegada por Carlos Cordeiro (2003: 245-247) permite establecer que, para este verbo, as formas en -e son esporádicas no occidente coruñés e concentradas no territorio tudense (Baiona, Sobroso, Salvaterra, Tebra), e que só andado o séc. XIV comezan a aparecer neste testemuños da forma innovadora en -o. Esta variación temperá está tamén presente nos textos que estudamos: disse (1255-Melón/Mondariz, 4v), dise disse (1260-Cereixo, 3v) / disso (c1253Ombre, 3v; 1257-Monfero, 2v).

$\mathrm{Na} 1 \mathrm{P}$ do Indicativo Presente de haber, ademais de hei e variantes gráficas, os textos galegos presentan unha forma primitiva aio (coas variantes agyo, agio, ayo, ajo...). Maia explica a primeira como forma reducida, orixinada en posición proclítica no seu uso como verbo auxiliar, en tanto que a segunda sería a forma plena (Maia 1986: 770). Os datos que achega a autora non 
son concluíntes, pois faltan formas en amplos dominios territoriais, pero en todo caso si podemos afirmar que todos os rexistros de aio se localizan nas dioceses de Mondoñedo e Lugo ou na súa inmediatez (Monfero, Viveiro, Lourenzá, Lugo, Portomarín, Deza, Caldelas), onde é minoritaria ei; en cambio, a forma ei aparece salferida, aparentemente sen competencia, en occidente. Nos primeiros textos atopamos aio (1243-Lourenzá, 1252-Veiga [5v]), ayo (1254-Vilafranca, 1255-Portomarín), agho (1259-Montederramo), agyo (1255-Maceda) e agio (1260-Pruzos), que confirman e amplían a localización nororiental; en todos eles haber ten carácter predicativo (v. gr., "quanta herdade eu agyo en Gĩjzo"). Na mesma área tamén ocorre ey, como predicativo (1240-Corgo, 1251-Veiga [3v], 1257-Casoio, 1260-Pruzos) ou como auxiliar («hey a_auer", 1243-Lourenzá).

Está tamén desde os inicios a variación entre sea e seja, poñendo en entredito a suposta influencia castelá para a primeira (Maia 1986: 828-829). Nos textos hai unha permanencia considerable das formas latinas sis-sit-sitis, do Subxuntivo Presente de sum, que non permiten saber que forma romance encobren $^{18}$; en menor medida rexístrase sedeant, do Subxuntivo Presente de SEDEO, que probablemente testemuña seja (1250-Montederramo). As solucións gráficas con $<\mathrm{i}, \mathrm{j}, \mathrm{y}, \mathrm{g}, \mathrm{gi}>$, que trasladan a palatal procedente de -DI-, son as maioritarias (61\%), pero en menor medida do que se desprende dos textos analizados por Maia. Todos estes nosos rexistros de sea-, coma a maior parte dos aducidos pola ilustre colega coimbrá, sitúanse nun espazo suroriental, limitado por Melón, Lugo e Vilafranca: sea (1231-Melón/Borbén [2v], 1240-Corgo, 1254-Vilafranca, 1255-Portomarín [6v], 1255-Trives [2v], 1257-Casoio, 1258-Monterroso), seea (1259-Montederramo), seã (1254-Vilafranca), seam (1258-Monterroso); con frecuencia son as máis temperás nos respectivos lugares, polo que, na nosa opinión, confirman un continuum antigo coas variantes leonesas e coas que se habían converter en normais no espazo castelán ${ }^{19}$.

18. Os datos son os seguintes: sis en 1251-Monterrei; sit en 1233 Melón/Covelo, 1243-Lourenzá, 1244-Veiga, 1250-Montederramo, 1251-Monterrei (3v), 1251-Veiga, 1257-Pallares, 1257-Meira, 1259-Guntín; sitis en c1253-Ombre (2v).

19. Os datos da outra variante son os seguintes: sega (1243-Lourenzá, 1247-Páramo, 1258-Friol [2v]), siga (1247-Páramo), segia (1260-Pruzos [2v.]), seia (1233-Melón/Covelo, 1241-Castañeira, 1243-Lourenzá, 1251-Veiga [3v], 1252-Veiga [2v], 1253-Ramallosa, 1256-Trives, 1257-Monfero, 1257-Meira [2v]), seiamos (1233 Melón), seiã (1255-Trives), seya (257-Castañeira, 1257-Casoio), seyã (1255-Maceda). En contra do que afirma Maia (1986), sexa non é o paradigma xeneralizado no galego moderno, pois, aínda que as Normas morfolóxicas vixentes consagran sexa (para os criterios, vid. RAG/ILG 2003: 163), esta variante apenas se rexistra nos traballos de campo ( $A L G a$ : I 366). Houbo, por tanto, unha recuperación e unha expansión de sea-, axudada ou non pola coincidencia formal co castelán. 
Non fixemos unha busca sistemática dalgúns trazos que sabemos que hoxe se dan con variación diatópica, polo que xa nos están anunciando que teñen interese para nós. Por exemplo, sen presumir nada sobre a distribución xeográfica en tempos tan recuados, o certo é que atopamos fumo (1228-Allariz) nunha área que hoxe ten ese trazo; e, máis sorprendente, moestiro (1259-Guntín), que a priori ten o aspecto de lapsus ou curiosidade gráfica, amósase xustamente en Ferreira de Pallares, nunha pequena área que hoxe se caracteriza, fronte a todas as outras variedades de galego, polas variantes castiro e macira ('castiñeiro, maceira', ALGa: II 112).

3. Finalmente, confirman que o cambio lingüístico non sempre progresa de forma lineal, pois o triunfo dunha forma vai acompañado de avances e retrocesos sobre o territorio. Nesta liña argumental, os primeiros testemuños de variación mostran con frecuencia a existencia dunha historia previa, oculta pola falta de textos en romanzo (cf., máis arriba, como exemplos, os comentarios a propósito de setembro/setembro ou de deu/dou); dito doutro xeito, nalgúns casos as formas que dominan nestas décadas iniciais da escrita en galego non son as máis próximas do étimo, como se esperaría nun esquema ideal, aínda que estas poden rexurdir con forza máis adiante. Por tanto, confírmase que a evolución non progresa en liña recta, polo que cómpre ter moi en conta as coordenadas espaciais e temporais en que se comproban os testemuños probatorios.

\section{APÉNDICE}

A maior parte dos textos fóronnos facilitados por Henrique Monteagudo [M], Ana I. Boullón [B] e Boullón / Monteagudo [B/M], que preparan a edición dunha escolma que axiña verá a luz. Os restantes fóronnos facilitados por Raquel Rodríguez Parada [R] e por Ramón Lorenzo [L]. A todos eles, o noso agradecemento. 


\begin{tabular}{|c|c|c|c|}
\hline ED. & Mes/Día & REDACTOR & FORMA DE CITA \\
\hline $\mathrm{M}$ & Abril, 29 & Nuno, not. concilij de Allariz & 1228-Allariz \\
\hline $\mathrm{M} / \mathrm{B}$ & Agosto, 25 & Pedro Rodriguez Manteyga & 1231-Melón/Borbén \\
\hline $\mathrm{M} / \mathrm{B}$ & Febreiro, 4 & Petrus Petri & 1233-Melón/Covelo \\
\hline $\mathrm{M} / \mathrm{B}$ & Decembro, 3 & Petrum Alfonsi & 1240-Corgo \\
\hline $\mathrm{R}$ & & Fernando el escriuan & 1241-Castañeira \\
\hline $\mathrm{M} / \mathrm{B}$ & & Ruy Pirit & c1242-Friol \\
\hline $\mathrm{M} / \mathrm{B}$ & Outubro, 15 & Petrus Johannis & 1243-Lourenzá \\
\hline $\mathrm{M} / \mathrm{B}$ & Xaneiro & Johanes & 1244-Veiga \\
\hline $\mathrm{M} / \mathrm{B}$ & Abril, 6 & Bartholomeus de Ulloa & 1247-Páramo \\
\hline $\mathrm{L}$ & Novembro & Pedro Caro & 1247-Maceda \\
\hline $\mathrm{M} / \mathrm{B}$ & Montederramo & Petrus Martini & 1250-Montederramo \\
\hline $\mathrm{M} / \mathrm{B}$ & Novembro, 27 & Petrus Martini das Maus & 1251-Monterrei \\
\hline $\mathrm{R}$ & & Migael Fernandez & 1251-Veiga \\
\hline $\mathrm{R}$ & & Frater Fernandus & 1252-Veiga \\
\hline $\mathrm{M} / \mathrm{B}$ & Xullo, 8 & Rodrigo Sanchiz & 1253-Ramallosa [Baiona/Nigrán] \\
\hline $\mathrm{M} / \mathrm{B}$ & Setembro, 14 & Lourenço Eanes & c1253-Ombre [Pontedeume] \\
\hline $\mathrm{M} / \mathrm{B}$ & Setembro & Sancho Perez & 1254-Vilafranca [do Bierzo] \\
\hline $\mathrm{M} / \mathrm{B}$ & Xaneiro, 22 & Pelagiu Iohanni & 1255-Trives \\
\hline $\mathrm{M} / \mathrm{B}$ & Xullo, 10 & Pelagius Iohannis & 1255-Trives \\
\hline $\mathrm{M} / \mathrm{B}$ & Xullo, 15 & Johan de Santiago & 1255-Portomarín \\
\hline $\mathrm{M} / \mathrm{B}$ & Xullo, 25 & Joham de Santiago & 1255-Portomarín \\
\hline $\mathrm{M} / \mathrm{B}$ & Agosto, 23 & [Pedro Moogo $]$ & 1255-Melón/Mondariz \\
\hline $\mathrm{M} / \mathrm{B}$ & Setembro, 22 & Gonçaluo Martiiz & 1255-Maceda \\
\hline $\mathrm{M} / \mathrm{B}$ & Decembro & Johan Fernandiz & 1255-Sobroso [Pontearas/Mondariz...] \\
\hline $\mathrm{M} / \mathrm{B}$ & Marzo, 1 & Pelagius Iohannis & 1256-Trives \\
\hline $\mathrm{R}$ & Abril & & 1257-Casoio [Carballeda de Valdeorras] \\
\hline $\mathrm{M} / \mathrm{B}$ & Abril, 26 & & 1257-Monfero \\
\hline $\mathrm{R}$ & Agosto & & 1257-Castañeira [prov. Zamora] \\
\hline $\mathrm{M} / \mathrm{B}$ & Novembro, 8 & Pedro Iohannis & 1257-Pallares [Guntín] \\
\hline $\mathrm{M} / \mathrm{B}$ & Decembro, 25 & Pedro Calvo & 1257-Meira \\
\hline $\mathrm{M} / \mathrm{B}$ & Xuño, 5 & Johannes de Leiro & 1258-Friol \\
\hline $\mathrm{M} / \mathrm{B}$ & Setembro, 17 & Sancius Moniz ¿? & 1258-Monterroso \\
\hline $\mathrm{M} / \mathrm{B}$ & Marzo, 31 & Petrus Martini & 1259-Montederramo \\
\hline $\mathrm{M} / \mathrm{B}$ & Xuño, 22 & Ffernandus & 1259-Guntín \\
\hline $\mathrm{M} / \mathrm{B}$ & Xaneiro, 11 & & 1260-Cereixo [Vimianzo] \\
\hline $\mathrm{B}$ & Outubro, 15 & Pedro Perez de Jenrozio & 1260-Pruzos \\
\hline $\mathrm{B}$ & Marzo, 26 & Pedro Perez de Jenrozio & 1260-Pruzos [Irixoa/Monfero...] \\
\hline $\mathrm{M} / \mathrm{B}$ & & [Nodiça do celareyro] & c1260-Caaveiro [A Capela] \\
\hline
\end{tabular}

